\title{
Inhibition dominates sensory responses in awake cortex
}

\author{
Bilal Haider, Michael Häusser, and Matteo Carandini \\ University College London
}

\begin{abstract}
The activity of the cerebral cortex is thought to depend on the precise relationship between synaptic excitation and inhibition ${ }^{1-4}$. In visual cortex, in particular, intracellular measurements have related response selectivity to coordinated increases in excitation and inhibition ${ }^{5-9}$. These measurements, however, have all been performed during anaesthesia, which strongly influences cortical state $^{10}$ and therefore sensory processing ${ }^{7,11-15}$. The synaptic activity evoked by visual stimulation during wakefulness is unknown. Here, we measured visually evoked responses - and the underlying synaptic conductances - in the visual cortex of anaesthetised and awake mice. Under anaesthesia, responses could be elicited from a large region of visual space ${ }^{16}$ and were prolonged in time. During wakefulness responses were more spatially selective and much briefer. Whole-cell patch-clamp recordings of synaptic conductances ${ }^{5,17}$ revealed a surprising difference in synaptic inhibition during the two conditions. Whereas under anaesthesia inhibition tracked excitation in amplitude and spatial selectivity, during wakefulness it was much stronger than excitation and exhibited extremely broad spatial selectivity. We conclude that during wakefulness cortical responses to visual stimulation are dominated by synaptic inhibition, restricting their spatial spread and temporal persistence. These results provide the first direct glimpse of synaptic mechanisms that control visual responses in the awake cortex.
\end{abstract}

To investigate the impact of wakefulness on the synaptic basis of visual selectivity, we performed local field potential (LFP) recordings and whole-cell recordings of membrane potential $\left(\mathrm{V}_{\mathrm{m}}\right)$ in layer $2 / 3$ of primary visual cortex $(\mathrm{V} 1)$ in both anaesthetised and awake mice.

We first examined spontaneous activity, and found it to be profoundly affected by wakefulness (Fig. 1a,b). Under two widely used anaesthetic regimes, slow fluctuations in both $\mathrm{V}_{\mathrm{m}}$ and LFP ${ }^{18}$ were common (Fig. 1a, Supplementary Fig. 4). During wakefulness these slow fluctuations were abolished and replaced by higher frequency activity in both $\mathrm{V}_{\mathrm{m}}$ and LFP (Fig. 1b, Supplementary Fig. 1). Indeed, in nearly all cases, $\mathrm{V}_{\mathrm{m}}$ was distributed unimodally during waking ${ }^{19,20}$, but bimodally during anaesthesia (Supplementary Fig. 1a,b). Spontaneous firing rates were similarly low in the two conditions (anaesthetised, $0.3 \pm 0.2$ spikes/s, $\mathrm{n}=14$; awake, $0.1 \pm 0.1$ spikes/s, $\mathrm{n}=14 ; p=0.07$ ). These results indicate that $\mathrm{V} 1$ in awake mice rarely exhibits the spontaneous fluctuations that are common in anaesthesia or sleep ${ }^{7,20}$ and that have been reported in area $\mathrm{S} 1$ of quietly awake mice ${ }^{11}$.

We next probed visual responses with flashed bars, and found a striking effect of wakefulness on response duration (Fig. 1c-f). Briefly flashed bars (100 ms duration, $1.5 \mathrm{~s}$ intervals) elicited long-lasting LFP responses under anaesthesia (Fig. 1c; $553 \pm 22 \mathrm{~ms}, \mathrm{n}=7$ mice) and much briefer responses during wakefulness (Fig. 1d; $171 \pm 11 \mathrm{~ms}, \mathrm{n}=7$ mice; $p<$

AUTHOR CONTRIBUTIONS: BH performed experiments; BH and MC performed analysis; BH, MH, and MC designed the study and wrote the paper.

The authors have no competing financial interests. 
0.001). This striking difference in LFP response duration was seen across the depth of cortex (Supplementary Fig. 2). Awake $\mathrm{V}_{\mathrm{m}}$ responses were also rapidly truncated (Fig. 1h; $148 \pm 31$ $\mathrm{ms}, \mathrm{n}=14$ ) compared to anaesthetised responses (Fig. 1g; $553 \pm 73 \mathrm{~ms}, \mathrm{n}=14$; Supplementary Fig. 3). These prolonged responses in both $V_{m}$ and LFP were remarkably similar across anaesthetic regimes, and persisted regardless of the depth of anaesthesia (Supplementary Figs. 4,5).

This marked difference in awake versus anaesthetised responses was not confounded by the presence of spontaneous alternations of excitability seen during anaesthesia (Fig. 2). We asked whether responses under anaesthesia differed when neurons were spontaneously hyperpolarized (Down) compared to depolarized $(\mathrm{Up})^{7}$. Once we corrected for the tendency of $\mathrm{V}_{\mathrm{m}}$ to spontaneously alternate between these states (Fig. 2c), we found that $\mathrm{V}_{\mathrm{m}}$ responses evoked from either state during anaesthesia were remarkably similar in amplitude and duration (Fig. 2e), and were much longer than responses during wakefulness (Fig. 2f).

Responses in awake mice were also more selective across visual space (Fig. 3a-e). $\mathrm{V}_{\mathrm{m}}$ responses were twice as spatially selective during wakefulness than under anaesthesia. This difference in spatial localization was even more pronounced for spikes ${ }^{21}$ (Fig. 3e), even when we accounted for sustained responses during anaesthesia by restricting spike counts to the earliest portion of the sensory response (0-200 ms; Supplementary Fig. 6).

Surprisingly, we observed fewer visually-evoked spikes during waking than under anaesthesia (Fig. 3b). This difference was particularly evident during stimulation of regions surrounding the centre of the receptive field. Under anaesthesia, stimuli in these regions evoked significantly more firing $(0.6 \pm 0.2$ spikes/trial) than blank stimuli $(0.3 \pm 0.2$ spikes/ trial; $p<0.001)$. In awake animals, instead, stimuli in this region produced no net increase in spikes above spontaneous activity $(0.08 \pm 0.03$ vs. $0.08 \pm 0.04 ; p=0.89)$.

The lower spike counts seen during wakefulness were also associated with a reduced variability in $\mathrm{V}_{\mathrm{m}}$ responses (awake $\mathrm{SD}, 3.5 \pm 0.03 \mathrm{mV}$; $\mathrm{n}=14$; anaesth $\mathrm{SD}, 4.4 \pm 0.03 \mathrm{mV}$, $\mathrm{n}=14, p<0.001)$. This lower variability reduced threshold crossings of awake $\mathrm{V}_{\mathrm{m}}$, despite peak responses that were on average more depolarized than those during anaesthesia (Fig. $3 \mathrm{~d})$. Spike threshold was not different in wakefulness $(-40.0 \pm 1.1 \mathrm{mV})$ and anaesthesia $(-40.0 \pm 1.2 \mathrm{mV}, p=0.6)$. However, spikes evoked during wakefulness were quickly followed by a significant and long-lasting hyperpolarization (Fig. 3f). We hypothesized that this hyperpolarization — and indeed the finer spatiotemporal resolution of awake responses — was indicative of enhanced synaptic inhibition.

To test this hypothesis, we blocked the intrinsic conductances 22,23 in single neurons, and recorded synaptic currents in voltage clamp mode near the reversal potentials for glutamatergic excitation and GABAergic inhibition (Supplementary Fig. 7). We then estimated the relative change in total conductance $(\Delta \mathrm{G}$; Supplementary Figs. 7, and 8$)$ visible at the soma ${ }^{24}$ in response to visual stimulation. Resting conductance and peak evoked conductance were unaffected by wakefulness (Supplementary Figs. 7). Therefore, differences between awake and anaesthetised $\mathrm{V}_{\mathrm{m}}$ must instead result from changes in the relative strength of excitatory and inhibitory conductances, $\Delta \mathrm{G}_{\mathrm{e}}$ and $\Delta \mathrm{G}_{\mathrm{i}}$.

Under anaesthesia, the estimated excitatory and inhibitory conductances behaved just as expected from previous studies 1 1,5,7,8,17,22,23,25,26 (Fig. 4a). Upon stimulation, increased excitation was quickly followed by inhibition, and thereafter the two covaried at a sustained and elevated level for hundreds of ms after stimulus offset. In other words, $\Delta \mathrm{G}_{\mathrm{e}}$ and $\Delta \mathrm{G}_{\mathrm{i}}$ were balanced, in that they had similar amplitude and time course. 
During wakefulness, instead, inhibition dominated excitation during the entire time course of the visual response (Fig. 4b). During the initial $100 \mathrm{~ms}$ of response, the ratio of inhibition $\Delta \mathrm{G}_{\mathrm{i}}$ to excitation $\Delta \mathrm{G}_{\mathrm{e}}$ was 1.4-2.9 (geometric mean divided-times geometric s.e.), significantly larger than the ratio of 0.7-1.0 measured under anaesthesia $(p<0.05$, one-tailed two-sample t-test; Supplementary Fig. 9). Inhibition remained above baseline significantly longer than excitation (by $29 \pm 13 \mathrm{~ms} ; p<0.001$ ), but both excitation and inhibition disengaged within $200 \mathrm{~ms}$, mirroring the rapid termination of awake $\mathrm{V}_{\mathrm{m}}$ and LFP responses observed earlier (cf. Fig. 1,2). Wakefulness also reduced the amplitude of $\Delta \mathrm{G}_{\mathrm{e}}$, presumably because the intracortical sources of excitation were themselves subject to the same enhanced inhibition as the recorded neuron.

Strikingly, in awake animals, visually evoked inhibition was strongly activated even by stimuli placed far away from the receptive field centre (Fig. 4d, Supplementary Fig. 9). During anaesthesia, by contrast, placing stimuli in these surrounding regions evoked little inhibition (Fig. 4c). Across all recordings in anaesthetised mice $(n=6), \Delta G_{i}$ over the first $100 \mathrm{~ms}$ of the response was 1.8-2.4 times larger for stimuli in the centre than in the surround (significantly $>1 ; p<0.005$, one-tailed t-test). In awake mice, instead, $\Delta \mathrm{G}_{\mathrm{i}}$ was remarkably unselective for position: it was not significantly different in amplitude whether elicited from the centre or from the surround $(p=0.07)$. In fact, in every neuron recorded during wakefulness ( $n=16$; Supplementary Fig. 9) the $\Delta G_{i}$ to $\Delta G_{e}$ ratio for surround stimulation that was greater than 1; across the population, the surround-evoked $\Delta \mathrm{G}_{\mathrm{i}}$ to $\Delta \mathrm{G}_{\mathrm{e}}$ ratio was 0.8-1.1 under anaesthesia and a much larger 2.7-3.5 during wakefulness $(p<0.01)$.

Although retinotopy is the primary determinant of sensory responses in visual cortex, synaptic conductances are known to also depend on stimulus orientation ${ }^{5,8,22,23}$. We asked whether changing stimulus orientation would have any effect on our observations. The results echoed those described above: regardless of stimulus orientation, during wakefulness $\mathrm{V}_{\mathrm{m}}$ responses were brief, and inhibition dominated across visual space (Supplementary Figs. 10 and 11).

Taken together, these data identify a novel characteristic of awake cortical processingelevated and spatially extended inhibition - that is associated with more spatiotemporally selective sensory responses (Fig. 4e). While previous measurements of sensory responses in anaesthetised animals have debated the exact role of inhibition ${ }^{1-5,7,8,17,22,23,25,26}$, our findings reveal that inhibition is a decisive factor in the awake cortex: it dominates excitation in amplitude and over time (Fig. 4b,d) and is evoked from regions of visual space that extend far beyond the central regions of the receptive field (Fig. 4e). This elevated inhibition during wakefulness is consistent with earlier suggestions ${ }^{11,27,28}$ and reveals a regime of sensory processing that could not be observed during anaesthesia or sleep, where more balanced excitation and inhibition are evoked from large regions of space and persist long after the stimulus has disappeared. Enhanced inhibition in the awake cortex is ideally poised to extinguish any spatial or temporal spread of feedforward activity elicited by a sensory input. Accordingly, during wakefulness, we observed a brisk and highly selective impulse response to spatially localized visual stimuli.

What factors might regulate the strength of inhibition in the awake cortex? Neuromodulators can desynchronize LFP and $\mathrm{V}_{\mathrm{m}}{ }^{29}$, depolarize interneurons ${ }^{30}$, and alter response reliability and sensory perception ${ }^{10,13,19}$. It will be important to examine such factors, including the contributions of laminar connectivity and interneuron subtypes ${ }^{1-4}$ to the elevated inhibitory conductances that we observed during wakefulness. Having identified inhibition as a major determinant of spatially selective and temporally succinct visual responses in the awake cortex, we suggest that behavioural factors such as attention and reward may also exert their influence by modulating inhibition. 


\section{Online Methods}

Female C57BL6J mice aged 4-6 weeks were used in both anaesthetised and awake recordings, and all procedures were performed under license from the UK Home Office in accordance with the Animal (Scientific Procedures) Act 1986.

\section{Recordings under anaesthesia}

Anaesthesia was induced with chlorprothixene $\left(10^{-5} \mathrm{mg} \mathrm{kg}^{-1} \mathrm{IP}\right)$ and urethane $(1.5 \mathrm{mg}$ $\mathrm{kg}^{-1}, 10 \%$ w/v IP; All data presented in Figs.1-4), or with chlorprothixene (as above) and isoflurane $(0.25-1 \%)$. Atropine sulfate $\left(0.07 \mathrm{mg} \mathrm{kg}^{-1} \mathrm{SC}\right)$ was injected to maintain clear airways, dexamethasone ( $\left.2 \mathrm{mg} \mathrm{kg}^{-1} \mathrm{IM}\right)$ was used to prevent edema, and rimadyl (4 mg $\mathrm{kg}^{-1} \mathrm{SC}$ ) was administered as an analgesic and anti-inflammatory. Body temperature was maintained at $37.1^{\circ}$ with a feedback regulated heating pad. A tracheotomy was performed (during urethane experiments), and animals were passively ventilated with pure $\mathrm{O}_{2}$. The stimulated eye was protected with a gas permeable contact lens. The unstimulated eye was gently sutured shut. A small headplate with chamber was implanted over monocular regions of visual cortex ( $0.5 \mathrm{~mm} \mathrm{~A}, 2 \mathrm{~mm} \mathrm{~L}$ from lambda suture). Two small $(<0.5 \mathrm{~mm})$ craniotomies were drilled (within 200-400 $\mu \mathrm{m}$ of each other) for the separate entry of LFP and patch pipettes. A third craniotomy was drilled over anterior retrosplenial cortex for insertion of an $\mathrm{Ag} / \mathrm{AgCl}$ reference wire. The dura was carefully removed just before insertion of whole-cell pipettes. Warm HEPES buffered artificial cerebrospinal fluid (aCSF, in mM: $135 \mathrm{NaCl}, 5.4 \mathrm{KCl}, 5 \mathrm{HEPES}, 1 \mathrm{MgCl}_{2}, 1.8 \mathrm{CaCl}_{2}$; $\mathrm{pH}$ 7.3) filled the chamber to prevent desiccation and maintain ionic balance.

\section{Recordings during wakefulness}

Awake mice were implanted with a lightweight headplate with chamber under isoflurane anaesthesia, and allowed to recover for two days. On the third day, animals were acclimated to head fixation for between 10-60 minutes, with sweet liquid reward given at the start and end of training. The duration of training was increased over 4-5 days until mice were sitting comfortably for 3 hours. On the day of recording, craniotomies as described above were performed under isoflurane anaesthesia, the animal was allowed to recover for 3 hours, and a single 3 hour recording session commenced. The dura was opened just before recording. Mice displayed frequent grooming, whisking, and postural adjustments during experiments. They were also given sweet liquid reward every 30 minutes to keep them comfortable and hydrated.

\section{Recordings}

Patch pipettes (4-7 M $\Omega$ ) were pulled on a Narishige PC-10 and filled with (in $\mathrm{mM}$ ): $135 \mathrm{~K}$ gluconate, $6 \mathrm{KCl}, 10 \mathrm{HEPES}, 4 \mathrm{MgATP}, 0.3 \mathrm{Na}_{2} \mathrm{ATP}$, 0.1 EGTA, 8 phosphocreatine, $\mathrm{pH}$ adjusted to 7.3 with $\mathrm{KOH}, 290-295 \mathrm{mOsm}$. For voltage clamp recordings, $\mathrm{K}$ gluconate was substituted with $140 \mathrm{Cs}^{+}$methanesulfonate. 0.5 QX-314 and 5 TEA were included to block voltage gated $\mathrm{Na}^{+}$and $\mathrm{K}^{+}$conductances. While searching for neurons, diffusion of blockers was limited by using low pressures (20-30 mBar); more importantly, the LFP electrode served as an internal control for visual responsiveness. LFP response amplitudes and tuning were unaltered after using pipettes containing channel blockers.

Whole cell recordings were obtained with a MultiClamp 700B in voltage clamp mode using standard techniques ${ }^{31}$. Pipette capacitance was neutralized before break-in. Average seal resistances for anaesthetised and awake voltage clamp recordings were $3.8 \pm 1.7 \mathrm{G} \Omega$ and 6.3 $\pm 1.3 \mathrm{G} \Omega$, respectively. Seal resistances for anaesthetised and awake current clamp recordings were $4.5 \pm 1.2 \mathrm{G} \Omega$ and $5.3 \pm 1.1 \mathrm{G} \Omega$, respectively. Initial access resistance ranged from 9-30 M $\Omega$. This value generally increased within a few minutes and then stabilized. If 
initial access was greater than $50 \mathrm{M} \Omega$ the recording was not included for further analysis. Access resistance during visual stimulation was not different between anaesthetised and awake recordings in current clamp (Anaesth: $36 \pm 6 \mathrm{M} \Omega$; Awake: $39 \pm 3 \mathrm{M} \Omega$ ) or voltage clamp (Anaesth: $38 \pm 5 \mathrm{M} \Omega$; Awake: $38 \pm 4 \mathrm{M} \Omega$ ). Access resistance was compensated online during voltage clamp recordings and optimized manually. Series compensation averaged $63 \pm 1 \%$, yielding an effective series resistance of $22 \pm 3 \mathrm{M} \Omega$ and $24 \pm 3 \mathrm{M} \Omega$ during anaesthetised and awake voltage clamp recordings, respectively. Junction potential was not corrected. Voltage division through the uncompensated series resistance was corrected offline ${ }^{17}$.

This method limits distortion of the somatically recorded current by ongoing voltage fluctuations and membrane capacitance ${ }^{5,22}$; however, due to the necessity of intrinsic current blockade, it also masks potential contributions of active dendritic conductances ${ }^{32}$. This method also requires multiple trials and holding potentials; it thus cannot assess the simultaneous relationship of excitation and inhibition within single trials ${ }^{33}$.

As in previous studies ${ }^{2,34}$, to better estimate excitatory conductance we used a holding potential of about $+20 \mathrm{mV}$ rather than $0 \mathrm{mV}$, as this mitigates the voltage decay across the dendrites. Current clamp recordings had zero current injection during stimulation protocols. Input resistance and series resistance were monitored between protocols with current pulse trains or voltage steps. Firing rate adaptation to supra-threshold pulses and broad spikewidths confirmed that our recordings were from regular spiking pyramidal neurons ${ }^{35}$. Across all anaesthetised $(\mathrm{n}=22 ;-305 \pm 27 \mu \mathrm{m})$ and awake $(\mathrm{n}=30 ;-279 \pm 27 \mu \mathrm{m})$ wholecell recordings, there was no significant difference in laminar depth $(p=0.94)$, as estimated from the micromanipulator reading after it was zeroed upon contact with the cortical surface.

\section{Acquisition, visual stimulation and analysis}

All analyses and acquisition were performed in MATLAB. $\mathrm{V}_{\mathrm{m}}$ was low-pass filtered at 20 $\mathrm{kHz}$; during voltage clamp, $\mathrm{I}_{\mathrm{m}}$ was low-pass filtered at $2 \mathrm{kHz}$; LFP was filtered from 0.1-100 Hz. Data was acquired via a National Instruments board and was synchronized to stimulus onset by a photodiode signal.

The LCD monitor was positioned $24 \mathrm{~cm}$ away from the mouse and at $0^{\circ}$ elevation and $30-45^{\circ}$ azimuth. The azimuthal position was adjusted so that the centre of the LFP receptive field was roughly centred on the screen. Stimuli were presented on a grey background, and randomly interleaved across space, with $8-20$ repetitions per stimulus location. A blank screen (the grey background) was randomly presented every 11 stimulus presentations, for the same duration as the stimulus trials. Stimuli were delivered monocularly. The unstimulated eye was gently sutured (anaesthetised) or shielded by black aluminium foil (awake). Throughout the entire recording session, the monitor was continuously illuminated with the same grey screen. This was to ensure that spontaneous cortical state was not affected by transitions to and from complete darkness of the monitor.

In awake recordings, upon establishing stable whole-cell configuration, 1-2 minutes of spontaneous activity was recorded before the presentation of any flashed bars. This data was used for all calculations of spontaneous activity (Figs. 1a-b, 2a-b; Supplementary Figs. 1,4); there were no systematic differences with the interleaved blank data. In some awake protocols we shortened the interstimulus interval (ISI) to $300 \mathrm{~ms}$ because the evoked responses returned to baseline well before this interval. There was no difference between the magnitude or duration of evoked conductances with longer $(1.5 \mathrm{~s})$ vs. shorter ISI $(\mathrm{n}=3)$. For measurements of $V_{m}$ (Figs. 2,3; Supplementary Fig. 3) any spikes were median filtered (7 $\mathrm{ms}$ ) and the resulting trace smoothed. 
In a subset of experiments, we optimized the orientation of flashed bars for each individual neuron (Fig. S10) by first presenting full screen drifting gratings (50\% contrast; spatial frequency 0.03 cycles / deg; temporal frequency $2 \mathrm{~Hz} ; 2$ s duration) varying randomly in orientation (30 degree steps). The preferred orientation was designated as the one that evoked the largest number of spikes (or largest depolarization of $\mathrm{V}_{\mathrm{m}}$ ), while the orthogonal orientation was 90 degrees away from preferred. Bars identical to all other experiments $(9$ degree width; $100 \mathrm{~ms}$ duration, $1.5 \mathrm{~s}$ or $0.3 \mathrm{~s} \mathrm{ISI}$ ) were then presented randomly across space along the two axes defined by the preferred and orthogonal orientations.

To obtain robust estimates of $\mathrm{V}_{\text {rev }}$ and $\Delta \mathrm{G}$ during the responses, we considered the response onset as the time when $\Delta \mathrm{G}$ was $5-10 \%$ above baseline for 10 consecutive ms. Across the population of neurons, this time point occurred $30-40 \mathrm{~ms}$ after stimulus onset, so $\mathrm{V}_{\mathrm{rev}}, \Delta \mathrm{G}$, $\Delta \mathrm{G}_{\mathrm{e}}$, and $\Delta \mathrm{G}_{\mathrm{i}}$ were averaged starting $40 \mathrm{~ms}$ after stimulus onset, across the population (Fig. $4 ; \mathrm{n}=5$ urethane anaesthesia, $\mathrm{n}=8$ awake; both groups tested identically with vertically oriented bars). Additional recordings of conductances under isoflurane anaesthesia $(n=1)$, and in awake mice presented bars varying in orientation $(n=4)$ were not included in these plots to maintain equivalent group comparison (but see Supplementary Fig. 9).

The state dependence of visual responses during anaesthesia (Fig. 2) was analysed by sorting trials (within neurons) by pre-stimulus $\mathrm{V}_{\mathrm{m}}$ level. The upper- and lower-most quartiles (that is, the $25 \%$ most depolarized and $25 \%$ most hyperpolarized non-overlapping trials) were then averaged across the population, and largely correspond to trials when stimuli where delivered in Up versus Down states, respectively ${ }^{36}$. Blank stimuli were also sorted in this manner in order to estimate the spontaneous state transitions from Down to $\mathrm{Up}$, and vice versa, in the absence of sensory stimulation.

\section{Supplementary Material}

Refer to Web version on PubMed Central for supplementary material.

\section{Acknowledgments}

We thank Tatsuo Sato, Aman Saleem and Asli Ayaz for help with procedures; Spencer L. Smith, Christoph Schmidt-Hieber and Kate Powell for advice on recordings, and Arnd Roth, Massimo Scanziani and David McCormick for comments. We are grateful to the National Science Foundation, European Research Council, Medical Research Council, Wellcome Trust, and Gatsby Charitable Foundation for financial support. MC holds the GlaxoSmithKline/Fight for Sight Chair in Visual Neuroscience.

\section{References}

1. Isaacson JS, Scanziani M. How inhibition shapes cortical activity. Neuron. 2011; 72:231-243. doi: 10.1016/j.neuron.2011.09.027. [PubMed: 22017986]

2. Atallah BV, Bruns W, Carandini M, Scanziani M. Parvalbumin-expressing interneurons linearly transform cortical responses to visual stimuli. Neuron. 2012; 73:159-170. [PubMed: 22243754]

3. Wilson NR, Runyan CA, Wang FL, Sur M. Division and subtraction by distinct cortical inhibitory networks in vivo. Nature. 2012; 488:343-348. doi:10.1038/nature11347. [PubMed: 22878717]

4. Lee $\mathrm{SH}$, et al. Activation of specific interneurons improves V1 feature selectivity and visual perception. Nature. 2012; 488:379-383. doi:10.1038/nature11312. [PubMed: 22878719]

5. Borg-Graham L, Monier C, Frégnac Y. Voltage-clamp measurement of visually evoked conductances with whole-cell patch recordings in primary visual cortex. J. Physiol. (Paris). 1996; 90:185-188. [PubMed: 9116665]

6. Cardin JA, Kumbhani RD, Contreras D, Palmer LA. Cellular mechanisms of temporal sensitivity in visual cortex neurons. J Neurosci. 2010; 30:3652-3662. doi:10.1523/JNEUROSCI.5279-09.2010. [PubMed: 20219999] 
7. Haider B, McCormick DA. Rapid neocortical dynamics: cellular and network mechanisms. Neuron. 2009; 62:171-189. doi:10.1016/j.neuron.2009.04.008. [PubMed: 19409263]

8. Marino J, et al. Invariant computations in local cortical networks with balanced excitation and inhibition. Nat Neurosci. 2005; 8:194-201. [PubMed: 15665876]

9. Priebe NJ, Ferster D. Inhibition, spike threshold, and stimulus selectivity in primary visual cortex. Neuron. 2008; 57:482-497. [PubMed: 18304479]

10. Harris KD, Thiele A. Cortical state and attention. Nat Rev Neurosci. 2011; 12:509-523. doi: 10.1038/nrn3084. [PubMed: 21829219]

11. Crochet S, Poulet JF, Kremer Y, Petersen CC. Synaptic mechanisms underlying sparse coding of active touch. Neuron. 2011; 69:1160-1175. doi:10.1016/j.neuron.2011.02.022. [PubMed: 21435560]

12. Gilbert CD, Sigman M. Brain states: top-down influences in sensory processing. Neuron. 2007; 54:677-696. doi:10.1016/j.neuron.2007.05.019. [PubMed: 17553419]

13. Goard M, Dan Y. Basal forebrain activation enhances cortical coding of natural scenes. Nat Neurosci. 2009; 12:1444-1449. doi:10.1038/nn.2402. [PubMed: 19801988]

14. Niell CM, Stryker MP. Modulation of visual responses by behavioral state in mouse visual cortex. Neuron. 2010; 65:472-479. doi:10.1016/j.neuron.2010.01.033. [PubMed: 20188652]

15. Worgotter F, et al. State-dependent receptive-field restructuring in the visual cortex. Nature. 1998; 396:165-168. doi:10.1038/24157. [PubMed: 9823895]

16. Bringuier V, Chavane F, Glaeser L, Frégnac Y. Horizontal propagation of visual activity in the synaptic integration field of area 17 neurons. Science. 1999; 283:695-699. [PubMed: 9924031]

17. Wehr M, Zador AM. Balanced inhibition underlies tuning and sharpens spike timing in auditory cortex. Nature. 2003; 426:442-446. doi:10.1038/nature02116. [PubMed: 14647382]

18. Steriade M, Nunez A, Amzica F. A novel slow (< $1 \mathrm{~Hz})$ oscillation of neocortical neurons in vivo: depolarizing and hyperpolarizing components. J Neurosci. 1993; 13:3252-3265. [PubMed: 8340806]

19. Constantinople CM, Bruno RM. Effects and mechanisms of wakefulness on local cortical networks. Neuron. 2011; 69:1061-1068. doi:10.1016/j.neuron.2011.02.040. [PubMed: 21435553]

20. Steriade M, Timofeev I, Grenier F. Natural waking and sleep states: a view from inside neocortical neurons. J Neurophysiol. 2001; 85:1969-1985. [PubMed: 11353014]

21. Simons DJ, Carvell GE, Hershey AE, Bryant DP. Responses of barrel cortex neurons in awake rats and effects of urethane anesthesia. Exp Brain Res. 1992; 91:259-272. [PubMed: 1459228]

22. Liu BH, et al. Broad inhibition sharpens orientation selectivity by expanding input dynamic range in mouse simple cells. Neuron. 2011; 71:542-554. doi:10.1016/j.neuron.2011.06.017. [PubMed: 21835349]

23. Tan AY, Brown BD, Scholl B, Mohanty D, Priebe NJ. Orientation selectivity of synaptic input to neurons in mouse and cat primary visual cortex. J Neurosci. 2011; 31:12339-12350. doi:10.1523/ JNEUROSCI.2039-11.2011. [PubMed: 21865476]

24. Williams SR, Mitchell SJ. Direct measurement of somatic voltage clamp errors in central neurons. Nat Neurosci. 2008; 11:790-798. [PubMed: 18552844]

25. Haider B, et al. Synaptic and network mechanisms of sparse and reliable visual cortical activity during nonclassical receptive field stimulation. Neuron. 2010; 65:107-121. doi:10.1016/j.neuron. 2009.12.005. [PubMed: 20152117]

26. Ozeki H, Finn IM, Schaffer ES, Miller KD, Ferster D. Inhibitory stabilization of the cortical network underlies visual surround suppression. Neuron. 2009; 62:578-592. doi:10.1016/j.neuron. 2009.03.028. [PubMed: 19477158]

27. Rudolph M, Pospischil M, Timofeev I, Destexhe A. Inhibition determines membrane potential dynamics and controls action potential generation in awake and sleeping cat cortex. J Neurosci. 2007; 27:5280-5290. doi:10.1523/JNEUROSCI.4652-06.2007. [PubMed: 17507551]

28. Swadlow HA. Thalamocortical control of feed-forward inhibition in awake somatosensory 'barrel' cortex. Philosophical transactions of the Royal Society of London. Series B, Biological sciences. 2002; 357:1717-1727. doi:10.1098/rstb.2002.1156. 
29. Steriade M, Amzica F, Nunez A. Cholinergic and noradrenergic modulation of the slow (approximately $0.3 \mathrm{~Hz}$ ) oscillation in neocortical cells. J Neurophysiol. 1993; 70:1385-1400. [PubMed: 8283204]

30. Arroyo S, Bennett C, Aziz D, Brown SP, Hestrin S. Prolonged disynaptic inhibition in the cortex mediated by slow, non-alpha7 nicotinic excitation of a specific subset of cortical interneurons. $\mathrm{J}$ Neurosci. 2012; 32:3859-3864. doi:10.1523/JNEUROSCI.0115-12.2012. [PubMed: 22423106]

31. Margrie TW, Brecht M, Sakmann B. In vivo, low-resistance, whole-cell recordings from neurons in the anaesthetized and awake mammalian brain. Pflugers Arch. 2002; 444:491-498. doi:10.1007/ s00424-002-0831-z. [PubMed: 12136268]

32. Branco T, Hausser M. Synaptic integration gradients in single cortical pyramidal cell dendrites. Neuron. 2011; 69:885-892. doi:10.1016/j.neuron.2011.02.006. [PubMed: 21382549]

33. Cafaro J, Rieke F. Noise correlations improve response fidelity and stimulus encoding. Nature. 2010; 468:964-967. doi:10.1038/nature09570. [PubMed: 21131948]

34. Poo C, Isaacson JS. Odor representations in olfactory cortex: "sparse" coding, global inhibition, and oscillations. Neuron. 2009; 62:850-861. doi:10.1016/j.neuron.2009.05.022. [PubMed: 19555653]

35. Nowak LG, Azouz R, Sanchez-Vives MV, Gray CM, McCormick DA. Electrophysiological classes of cat primary visual cortical neurons in vivo as revealed by quantitative analyses. J Neurophysiol. 2003; 89:1541-1566. [PubMed: 12626627]

36. Haider B, Duque A, Hasenstaub AR, Yu Y, McCormick DA. Enhancement of visual responsiveness by spontaneous local network activity in vivo. J Neurophysiol. 2007; 97:41864202. [PubMed: 17409168] 

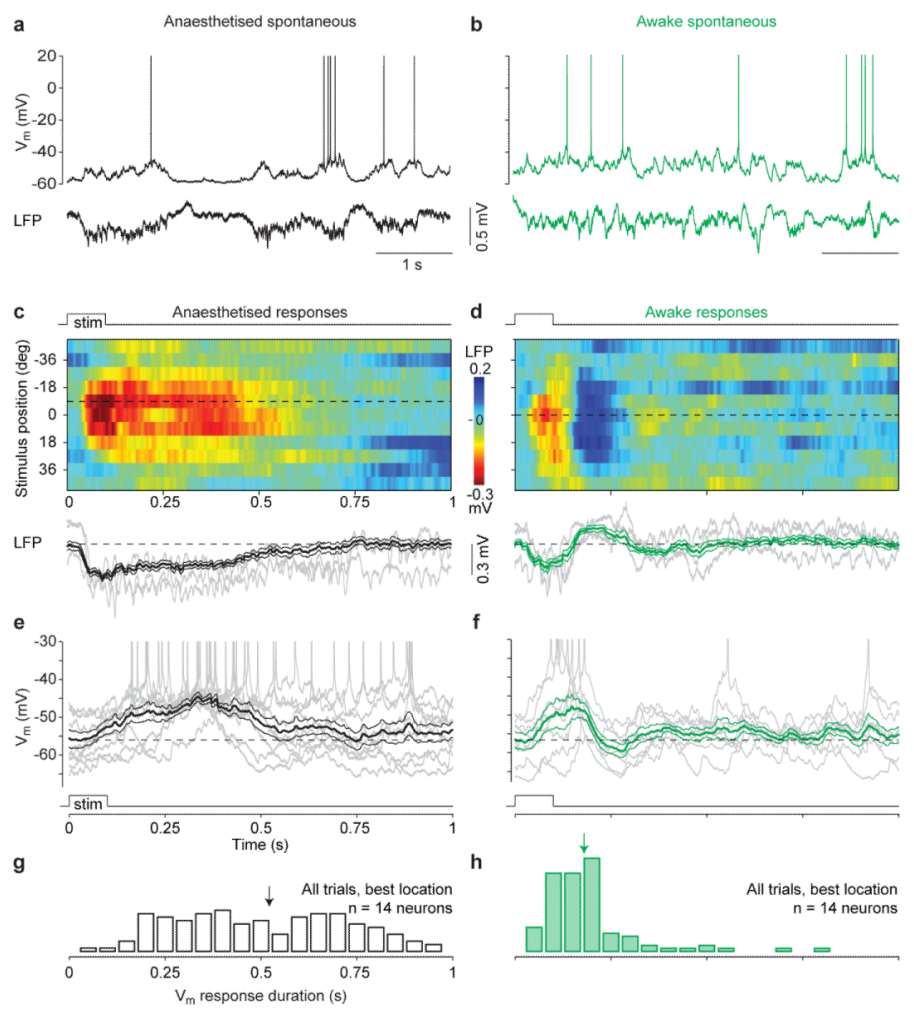

Figure 1.

Spontaneous and evoked activity in anaesthetised versus awake V1

a) Spontaneous membrane potential $\left(\mathrm{V}_{\mathrm{m}}\right)$ and simultaneous local field potential (LFP) measured in V1 under anaesthesia. Spikes truncated.

b) Same as a, during wakefulness.

c) Visually evoked LFP response across space during anaesthesia. Averages of 15 trials per location. Dashed line, best location. Bottom, single trial (grey) and average (black) responses at best location.

d) Same as c, during wakefulness.

e) Anaesthetised $V_{m}$ responses to stimuli at best location, single trials (grey) and average (black, \pm SEM). Spikes truncated.

f) Same as e, during wakefulness. c-f from 4 different mice.

g) Distribution of $\mathrm{V}_{\mathrm{m}}$ response durations at best location, across population $(\mathrm{n}=14)$, measured under anaesthesia. Arrow: mean duration.

h) Same as g, during wakefulness. 
a

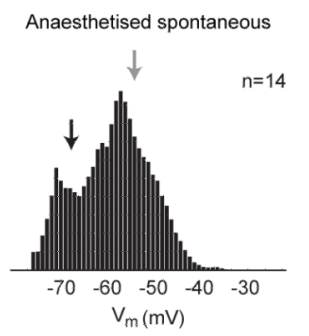

c

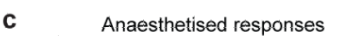

Anaesthetised responses

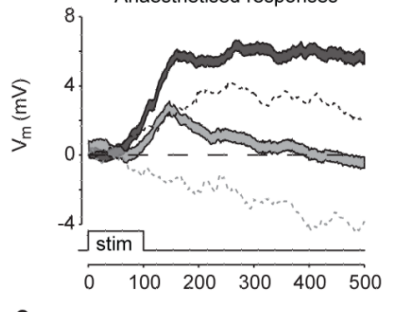

e

$\underset{\triangleleft}{\overbrace{}^{E}}$

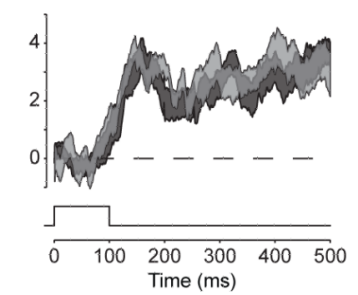

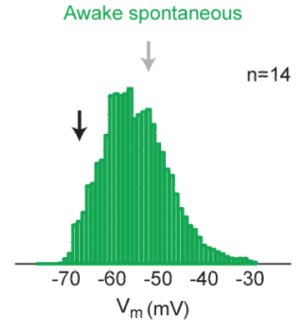

d
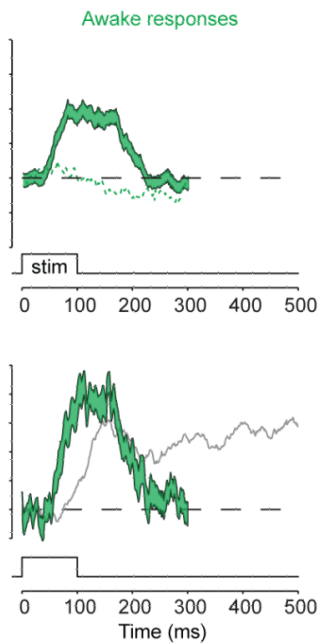

Figure 2.

Anaesthetised responses are long lasting regardless of cortical state.

a) Distribution of spontaneous $V_{m}$ during anaesthesia ( $n=14$ neurons).

b) Same as a, during wakefulness ( $\mathrm{n}=14$ neurons).

c) Average ( \pm SEM) anaesthetised $V_{m}$ responses, sorted by pre-stimulus $V_{m}$ level. Means of depolarized (black) and hyperpolarized (grey) groups (indicated by arrows in a). Prestimulus baseline $\mathrm{V}_{\mathrm{m}}$ was subtracted before averaging. Dashed lines indicate average spontaneous $\mathrm{V}_{\mathrm{m}}$ (blank stimuli), sorted similarly into two groups.

d) Same as c, during wakefulness $(\mathrm{n}=14)$.

e) Average anaesthetised $V_{m}$ response for hyperpolarized (black) and depolarized (grey) trials, after subtraction of spontaneous $\mathrm{V}_{\mathrm{m}}$ traces.

f) Same as e, during wakefulness. Light grey line: Grand average of all anaesthetised responses (for comparison). 

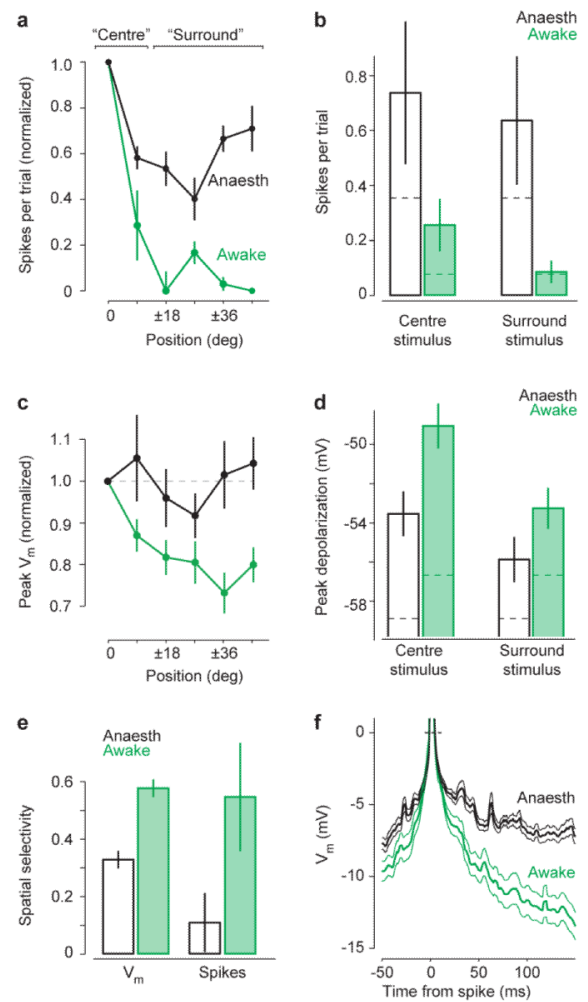

Figure 3.

Responses are spatiotemporally restricted during waking

a) Evoked spikes per trial (normalized by each neuron's response at best location). Symmetric locations on either side of zero combined. "Centre" defined as $0 \pm 9^{\circ}$; "Surround" as $\pm 18-45^{\circ}$. Response window defined by average duration of population $\mathrm{V}_{\mathrm{m}}$ response (Fig. 1g,h). n=14 for each group. \pm SEM throughout figure.

b) Under anaesthesia (black), centre (left) and surround (right) stimuli evoked more spikes ( $p<0.001$ for both) than during spontaneous activity (dashed). During wakefulness (green) spikes were fewer than under anaesthesia ( $p<0.001$ for both); centre evoked more spikes than surround $(p<0.009)$, and surround was not significantly different from spontaneous. $9 / 14$ neurons active during anaesthesia, 5/14 active during waking.

c) Same as a, for peak $V_{m}$ responses (normalized by each neuron's response at best location).

d) Same as b, for peak $\mathrm{V}_{\mathrm{m}}$ responses. Centre responses were greater than surround responses in both conditions $(p<0.04$ for both), and all responses were greater than spontaneous activity (dashed lines, $p<0.001$ for all). Awake responses were larger than anaesthetised responses ( $p<0.001$ for both).

e) $\mathrm{V}_{\mathrm{m}}$ and spike responses were more spatially selective during waking. $\left(\mathrm{V}_{\mathrm{m}}\right.$ : anaesthetised, $0.3 \pm 0.06$; awake, $0.6 \pm 0.06 ; p<0.001$; Spikes: anaesthetised $0.1 \pm 0.1$; awake, $0.6 \pm 0.2$; $p<0.001$ ).

f) Spike-triggered average of $V_{m}$ under anaesthesia (black) and wakefulness (green). Spike threshold (peak of second derivative of $\mathrm{V}_{\mathrm{m}}$ ) aligned at $0 \mathrm{mV}$. 

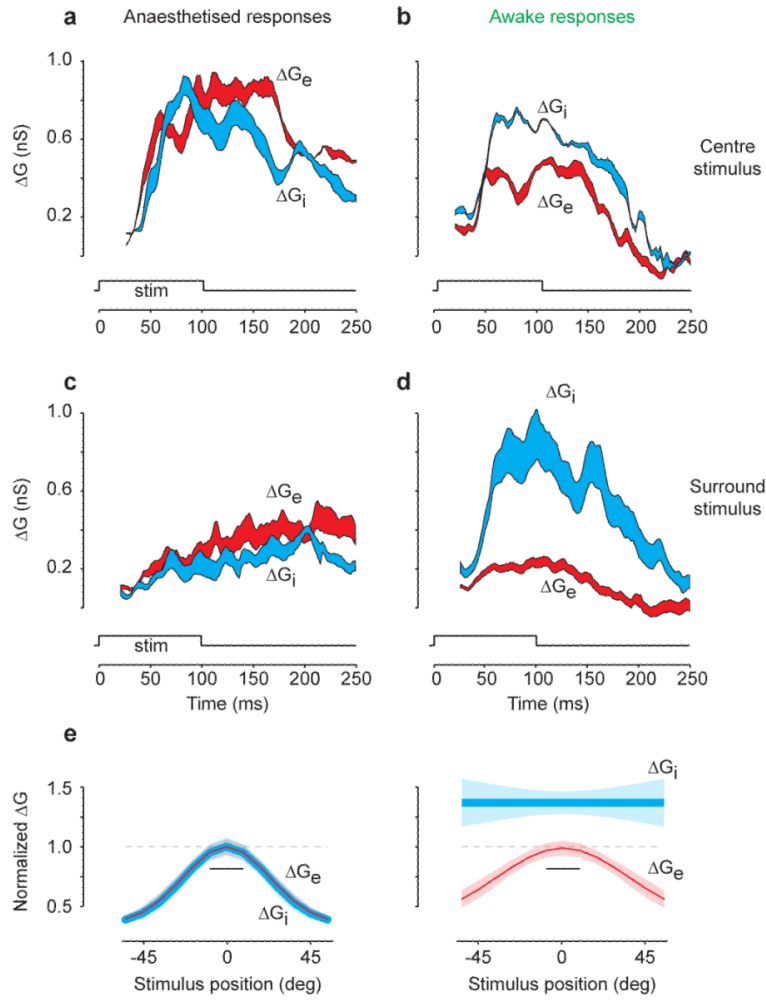

Figure 4.

Visually evoked conductances are dominated by inhibition in awake V1.

a) $\Delta \mathrm{G}_{\mathrm{e}}$ and $\Delta \mathrm{G}_{\mathrm{i}}$ evoked by centre stimulation during anaesthesia $(\mathrm{n}=5) . \pm \mathrm{SEM}$ throughout.

b) Same, during waking $(\mathrm{n}=8)$.

c) $\Delta \mathrm{G}_{\mathrm{e}}$ and $\Delta \mathrm{G}_{\mathrm{i}}$ evoked by surround stimulation during anaesthesia. Same neurons as a.

d) Same, during waking. Same neurons as b.

e) Spatial profiles of excitation and inhibition under anaesthesia (left) versus wakefulness (right). $\Delta \mathrm{G}_{\mathrm{e}}$ (red) and $\Delta \mathrm{G}_{\mathrm{i}}$ (blue) normalized to peak $\Delta \mathrm{G}_{\mathrm{e}}$ at centre (grey dashed line) for each neuron and averaged across population. Data were fitted with Gaussian $( \pm \mathrm{SD}$, shaded) or linear (awake $\mathrm{G}_{\mathrm{i}}, \pm \mathrm{SD}$ ) functions. Scale bar, $18^{\circ}$ width across RF centre. 